\title{
Influence of the Dopant Gas Precursor in p- type Nanocrystalline Silicon Layers on the performance of front junction Heterojunction Solar Cells
}

\author{
Luca Antognini, Vincent Paratte, Jan Haschke, Jean Cattin, Julie Dréon, Mario Lehmann, Laurie- \\ Lou Senaud, Quentin Jeangros, Christophe Ballif, Mathieu Boccard
}

\begin{abstract}
Silicon heterojunction solar cells can employ p-type hydrogenated nanocrystalline silicon nc-Si:H(p) on their front side, since these can provide better transparency and contact resistance compared to hydrogenated p-type amorphous silicon layers. We investigate here the influence of trimethyl boron (TMB) and $\mathrm{BF}_{3}$ as dopant source on the layer properties and its performance in solar cells. Both gases enable high efficiencies but yield a different crystallinity and effective doping. A high $\mathrm{BF}_{3}$ flow lowers the series resistance through a low activation energy of dark lateral conductivity and maintains a high crystallinity. This allows fill factors up to $83 \%$, however with the apparition of a parasitic absorption in the UV. A low TMB flow enables simultaneously a high crystallinity and a low activation energy. As an illustration of this layer potential, a $23.9 \%$-certified efficiency is achieved with a $2 \times 2 \mathrm{~cm}^{2}$ screen-printed device. We finally suggest that similar transport vs. transparency trade-offs can be reached for both dopant types for front junction application, while high $\mathrm{BF}_{3}$ flow allowing lower series resistance might be of interest when placed on the rear side.
\end{abstract}

Index Terms - heterojunction, carrier-selective contact, nanocrystalline silicon p-layer, passivating contact, thin films, dopant precursor gas.

Manuscript received January xx, 2021. This project has received funding from the Swiss national science foundation under Ambizione Energy grant ICONS (PZENP2_173627) as well as under the grant no. 200021L_172924/1.

L. Antognini, V. Paratte, J. Cattin, J. Dréon, M. Lehmann, Q. Jeangros, C. Ballif, and M. Boccard are with the École Polytechnique Fédérale de Lausanne (EPFL), Institute of Microengineering (IMT), Photovoltaics and Thin Film Electronics Laboratory, Rue de la Maladière 71b, CH-2002 Neuchâtel, Switzerland (corresponding author: +41 21695 4235; fax: +41 21 695 4201; e-mail: luca.antognini@epfl.ch).

J. Haschke was with École Polytechnique Fédérale de Lausanne (EPFL), Institute of Microengineering (IMT), Photovoltaics and Thin Film Electronics Laboratory, Rue de la Maladière 71b, CH-2002 Neuchâtel, Switzerland. He is now with REC Solar Pte. Ltd., 20 Tuas South Ave. 14, Singapore 637312, Singapore.

L.-L. Senaud is with the Centre Suisse d'Electronique et de Microtechnique SA (CSEM), Rue Jaquet-Droz 1, 2002 Neuchâtel, Switzerland.

\section{INTRODUCTION}

$\mathrm{T}$ HE silicon heterojunction (SHJ) technology enables reaching conversion efficiency of up to $25.1 \%$ for doubleside contacted solar cells [1],[2], 26.7\% for interdigitated back contact cells [3], and average efficiency above $23 \%$ in several laboratories and production industries [4],[5],[6]. Standard SHJ designs use hydrogenated amorphous silicon (a$\mathrm{Si}: \mathrm{H})$ for both surface passivation (a-Si:H(i)) and selective layers (a-Si:H(n) and a-Si:H(p)), completed by indium tin oxide (ITO) for lateral charge transport and anti-reflection. Although these layer stacks enable excellent surface passivation and carrier selectivity, SHJ solar cells suffer from important parasitic light absorption and possible charge transport losses due to the relatively low transparency [7] and doping efficiency of a-Si:H [8],[9], respectively. Replacing the doped a-Si:H layers by nanocrystalline silicon (nc-Si:H(n) and nc-Si:H(p)) is a promising route to improve the efficiency of SHJ [10] or to simplify the manufacturing process of IBC solar cells [11]. Requirements to develop a good crystalline contact include: 1) obtaining a fast nucleation of the crystalline phase of the doped nc-Si:H layers on top of the passivation a-Si:H(i) layer, 2) reaching a high crystallinity to benefit from the higher transparency and doping efficiency of the crystalline phase, 3 ) using plasma conditions that don't hinder passivation [10].

For the development of the n-doped contact, $\mathrm{PH}_{3}$ is commonly used as the dopant precursor gas. In Ref. [12], excellent solar cell results were obtained in a rear junction (RJ) configuration, i.e. with the n-layer at the front, with solar cells reaching an efficiency of up to $23.4 \%$. The high transparency and the good contact properties of the nc-Si:H(n) were made possible by introducing a non-doped nc-Si:H seed layer of $\sim 5 \mathrm{~nm}$, which enhances the crystallinity of the subsequent $\sim 20 \mathrm{~nm}$-thick n-doped layer. By thinning down the layer to below $10 \mathrm{~nm}$ and alloying it with oxygen (to form a 
nc-SiOx:H(n) layer), it was possible to boost even more the transparency of the contact in RJ solar cell while keeping good transport properties [13],[14]. Finally, a remarkable $25.1 \%$ efficiency device was obtained on a full size n-type M2 monocrystalline-silicon, featuring a $20 \mathrm{~nm}$ nc-SiOx:H(n) layers at the front together with optimized passivation layers $\left(J_{s c}=39.55 \mathrm{~mA} / \mathrm{cm}^{2}, \mathrm{FF}=85.0 \%, V_{o c}=747 \mathrm{mV}\right)[2]$.

On the hole-selective-contact side, nc-SiOx:H(p) layers are more difficult to obtain with similar transparency and transport properties compared to their (n)-type counterparts, making the front junction (FJ) configuration less attractive [15]. Indeed, it was reported to be challenging to obtain both a high crystallinity for layers thinner than $\sim 20 \mathrm{~nm}$ and a dark conductivity activation energy $\left(\mathrm{E}_{\mathrm{A}}\right)$ approaching the low values reached with $n c-S i O x: H(n)\left(E_{A}\right.$ of $\sim 80 \mathrm{meV}$ for $p$ layers compared to $30 \mathrm{meV}$ for $\mathrm{n}$ layers [16]). These facts often motivate the $\mathrm{p}$-doped layer's placement at the rear side, enabling the use of thicker or more highly doped materials thanks to lower optical transparency constraints [17]. However, by introducing an oxide pre-treatment [18] and investigating substrate temperature lower than $200{ }^{\circ} \mathrm{C}$ [19] to promote crystallinity (see Fig. 4) without impacting passivation, solar cell efficiency of $23.5 \%$ were demonstrated as well with nc-Si:H(p) in front junction configuration, mainly enabled by the lower contact resistance [20]. In the present contribution, we will build upon those previous developments.

Overall, the incorporation of nc-Si:H layers in solar cells was studied in several ways, such as: i) varying the PECVD parameters (frequency, pressure, substrate temperature, the dilution ratio $\mathrm{D}=\left[\mathrm{H}_{2}\right] /\left[\mathrm{SiH}_{4}\right]$ ) [10]; ii) varying the silicon precursor gas [10]; iii) developing different incubation layers and surface pre-treatments [10] and iv) investigate the influence on the subsequent TCO growth [21]. Out of the directions that remain to investigate, the impact of the boron doping and boron gas precursor $\left(\mathrm{B}_{2} \mathrm{H}_{6}, \mathrm{BF}_{3}\right.$ and $\mathrm{B}\left(\mathrm{CH}_{3}\right)_{3}$, also named TMB for trimethylborane) are still to clarify. An ellipsometric study reported that films prepared with $\mathrm{B}_{2} \mathrm{H}_{6}$ exhibit a delayed nucleation compared to their $\mathrm{PH}_{3}$ and intrinsic counterparts [22]. Similarly, a higher ratio $\mathrm{D}=$ $\left[\mathrm{B}_{2} \mathrm{H}_{6}\right] /\left[\mathrm{SiH}_{4}\right]$ leads to a lower Raman crystallinity and smaller crystallite sizes measured via XRD [23]. However, the influence of boron on crystallinity is not trivial. In Ref. [24], using real-time spectroscopic ellipsometry, it was found that $\mathrm{B}_{2} \mathrm{H}_{6}, \mathrm{TMB}$, and $\mathrm{BF}_{3}$, combined with an adequate surface treatment (e.g., $\mathrm{H}$ plasma treatment for $\mathrm{TMB}$ and $\mathrm{BF}_{3}$ ), a high dilution ratio of $\mathrm{R}=\left[\mathrm{H}_{2} / \mathrm{SiH}_{4}\right]=200$, doping level $(\mathrm{D}=0.01$ for $\mathrm{B}_{2} \mathrm{H}_{6}$ and TMB, $\mathrm{D}=0.02-0.05$ for $\mathrm{BF}_{3}$, with $\mathrm{D}=[\mathrm{X}] /[\mathrm{SiH} 4]$ where $[\mathrm{X}]$ is the dopant flow) and plasma power $(\mathrm{P}=200$ $\mathrm{mW} / \mathrm{cm}^{2}$ for $\mathrm{B}_{2} \mathrm{H}_{6}$ and $\mathrm{TMB}, \mathrm{P}=700 \mathrm{~mW} / \mathrm{cm}^{2}$ for $\mathrm{BF}_{3}$ ) yield similarly dense, single-phase nc-Si:H layers. This study also evidenced several advantages of $\mathrm{BF}_{3}$ such as: i) avoiding carbon incorporation; ii) a wider precursor gas flow range yielding a crystalline regime and iii) a tolerance to higher plasma power and lower hydrogen-to-silane dilution leading to higher deposition rates without impinging crystallinity [24]. Finally, in Ref. [25], by comparing SIMS measurement and Raman crystallinity, a dopant-to-silane dilution range was identified where the boron concentration can be increased by several orders of magnitude without affecting crystallinity.

In the present publication, we aim to clarify the influence of the dopant source on the $\mathrm{nc}-\mathrm{Si}: \mathrm{H}(\mathrm{p})$ transparency and contact properties and its integration in solar cells. Hereafter, we present two batches of solar cells. First, with a "TMB and $\mathrm{BF}_{3}$ doping series", we study the impact of the TMB and $\mathrm{BF}_{3}$ flow on layers of similar thicknesses and report on their crystallinity using UV-Raman spectroscopy, the dopant inclusion using dark conductivity measurement, and their chemical composition measured via SIMS. Second, with a "BF 3 -doped layer thickness series", we study the optical impact of using a high $\mathrm{BF}_{3}$ flow. Optimization possibilities using both types of dopant sources are finally discussed, and front-junction devices featuring a $<30$ nm-thick nc-Si:H(p) allowing properties as good as their rear-junction counterparts are demonstrated. Finally, employing a double-antireflective coating, a $2 \times 2 \mathrm{~cm}^{2}$ solar cell with a certified efficiency of $23.92 \%$ is presented, featuring a nc-Si:H (p) layer on the front side and a single screen-print step.silicon is the main photovoltaic absorber material since many decades, and this domination is set to last for a few more years considering the current evolution of the market [26].

\section{EXPERIMENTAL DETAILS}

\section{A. Solar cell preparation}

The structure of the solar cells described in this section can be seen in

Figure 1. The solar cell preparation was based on 4', , 2 (cm, n-type FZ c-Si wafers. They were first placed in an alkaline etching solution to create random pyramids with an orientation (111) on both sides, resulting in a wafer thickness of $\sim 195 \mu \mathrm{m}$. The wafers were then chemically cleaned. The native oxide was removed using a one minute bath in $5 \%$ diluted HF.

The silicon layers were deposited via PECVD in a parallelplate plasma box KAI-M system at a frequency of $13.56 \mathrm{MHz}$. The latter is composed of two chambers dedicated to intrinsic and doped layers, respectively.

The solar cells were fabricated in a front-junction configuration. All intrinsic layers were deposited at a substrate temperature of $200{ }^{\circ} \mathrm{C}$ while all the other PECVD layers are deposited in a dedicated chamber at $175^{\circ} \mathrm{C}$. First, a 7 to 10 
nm-thick a-Si:H(i) layer was deposited for passivation on the backside, followed by an a-Si:H(n) / nc-Si:H(n) stack (or "in"

(a)

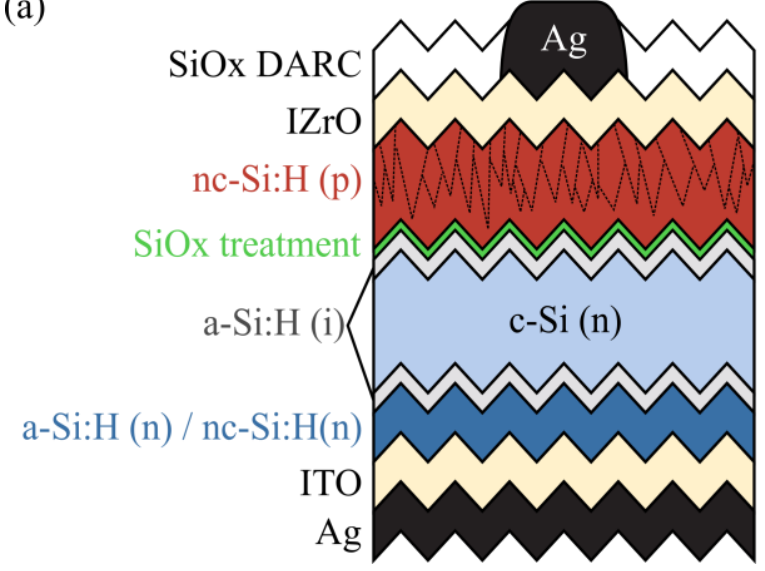

stack).

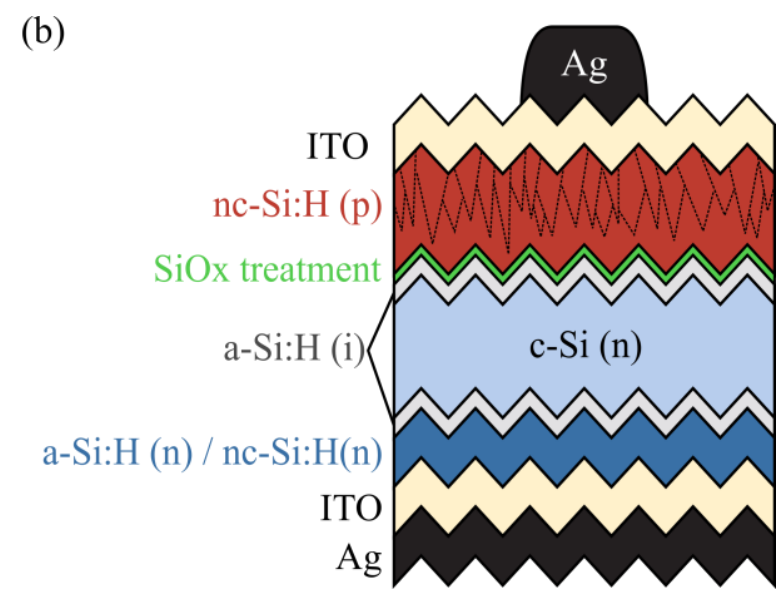

Figure 1. Scheme of the solar cells processed in this study. (a) Samples of the " TMB and BF3 doping series" (b) Samples of the "BF3-doped layers thickness series".

For the deposition of the front ip stack, we used two different strategies for the two batches presented in this study in order to avoid process artifacts that could be present in a non-industrial environment. They differ notably by the coating of the chamber and holding plate as well as the waiting time introduce between the process of the different layers:

i. For the "TMB and $\mathrm{BF}_{3}$ doping series", first the a-Si:H(i) front layer was co-deposited on all samples in the same condition as the rear a-Si:H(i) layer. Then all samples were removed and stored in nitrogen. After a p-type coating of the doped chamber and holder plate, each sample was processed individually: a 1-2nm $\mathrm{SiO}_{\mathrm{x}}$ layer was deposited on top of the a-Si:H(i) layer using a gas mixture of $\mathrm{SiH}_{4}, \mathrm{CO}_{2}$, and $\mathrm{H}_{2}$. The role of this seed layer was to enhance the crystallinity of the subsequent nc-Si:H(p) layer without damaging the surface passivation [27]. Then, the nc-Si:H(p) layer was finally deposited with a hydrogen dilution of $\mathrm{R}=\left[\mathrm{H}_{2}\right] /\left[\mathrm{SiH}_{4}\right]=133$, a varying dopant gas flow of 3 and $9.5 \mathrm{sccm}$ for TMB and 9.5 and $50 \mathrm{sccm}$ for $\mathrm{BF}_{3}$ (both being diluted at $98 \%$ in $\mathrm{H}_{2}$ corresponding to dilutions of $\mathrm{D}=[\mathrm{X}] /[\mathrm{SiH} 4]$ of $0.004,0.013,0.066$ respectively, with $[\mathrm{X}]$ being the actual TMB or $\mathrm{BF}_{3}$ concentration). This sequence resulted in the "ip" stack.

ii. For the " $\mathrm{BF}_{3}$-doped layer thickness series", to avoid possible artifacts coming from air exposure and waiting time of the samples after the front a-Si:H(i) layer deposition, the ip stacks of each sample were processed in a single process without interruption. However, in this approach, the i-layer could be impacted by the previous nc-Si:H(p) deposition on the holder plate, the latter containing more or less dopant depending on the previous layer deposited. This, in turn, could affect the collection efficiency of the i-layer [7], affecting the current of the solar cell and hindering our conclusions on the $\mathrm{BF}_{3}$ absorption properties. We thus included in this fabrication batch similar solar cells to characterize this effect, where only the doped chamber and holder plate coating before the ip stack deposition is changed.

Next, for the "TMB and $\mathrm{BF}_{3}$ doping series", a $\sim 125 \mathrm{~nm}$ (flat equivalent) indium zirconium oxide TCO allowing a higher mobility than ITO for same optical properties (See [28],[29]) was deposited on the front side via RF-sputtering in a MRC-II system using a target of $2 \%$ weight of $\mathrm{ZrO}_{2}$ in $\mathrm{In}_{2} \mathrm{O}_{3}$ with gas flow ratio of $[\mathrm{Ar}],\left[\mathrm{H}_{2}\right]$ and $\left[\mathrm{O}_{2}\right]$ of $99.2 \%, 0.4 \%$ and $0.4 \%$ respectively, a pressure of $10 \mathrm{mT}$ Torr and a power density of $1.65 \mathrm{~W} / \mathrm{cm}^{2}$. The deposition was made through a shadow mask defining five 2 x $2 \mathrm{~cm}^{2}$ solar cells per wafer. Subsequently, using DC-sputtering, a 220 nm-thick (flat equivalent) ITO was deposited on the full area of the backside followed by a $\sim 100 \mathrm{~nm}$-thick (flat equivalent) $\mathrm{Ag}$ blanket. Contacting of the solar cells was performed by screen-printing a silver grid on the front side using a curing temperature of $210{ }^{\circ} \mathrm{C}$ for 30 minutes in a belt furnace.

Finally, a 100 nm-thick PECVD SiOx layer was deposited at $180{ }^{\circ} \mathrm{C}$ on the front side to form a double anti-reflective coating (DARC) [30],[31]. This minimizes the reflectance of the solar cell and reduces the TCO sheet resistance $\left(R_{\text {sheet }}\right)$ [21],[32], thus allowing to observe more clearly the impact of the contact resistance of the hole-selective stack on the total series resistance. IV measurements before $\mathrm{SiO}_{\mathrm{x}}$ deposition are given in the Appendix (Fig. 8), showing that the $R_{\text {sheet }}$ variation among the sample has been reduced to lower than $15 \Omega / \mathrm{sq}$.

For the "BF ${ }_{3}$-doped layers thickness series", a simpler single ARC was realized on the front side with a $\sim 120$ nm-thick (flat 
equivalent) ITO layer. It was deposited via DC-sputtering on a $\mathrm{In}_{2} \mathrm{O}_{3}(90): \mathrm{SnO}_{2}(10)$ target with a gas flow ratio of $[\mathrm{Ar}]$ to $\left[\mathrm{O}_{2}\right]$ of $98 / 2$, at a pressure of $8 \mathrm{mTorr}$, a power of $\sim 2.2 \mathrm{~W} / \mathrm{cm}^{2}$.

Finally, the certified solar cell presented at the end of the study was produced using the same process order as the "TMB and $\mathrm{BF}_{3}$ doping series". It was then placed in forward-bias in the dark for two weeks, with a current flow of $40 \mathrm{~mA} / \mathrm{cm}^{2}$ corresponding to a carrier injection in the wafer similar to open-circuit condition under one sun. This step improves the surface passivation similarly to the beneficial effect of lightsoaking [33].

\section{B. Solar cell characterization}

Along the process flow, the lifetime and implied $V_{\text {oc }}$ were measured after the deposition of the in-i and in-ip stacks using a WCT-120 photoconductance lifetime tester in the transient analysis mode. IV curves of each solar cell were collected using a Wacom Electric Co. Super solar simulator with AM $1.5 \mathrm{G}$ illumination. Series resistance $\left(R_{\mathrm{s}}\right)$ at Maximum Power Point (MPP) and Fill Factors without the effects of $R_{s}$ (FF0) were obtained by comparing the IV curve of a device at 1 Sun with the one at 0.05 Sun using the method described in [34]. External quantum efficiency (EQE) curves were collected using a system developed in-house with a lock-in amplifier and a xenon arc lamp shining a $1 \times 1.5 \mathrm{~mm}^{2}$ monochromatic light spot between the grid fingers of the solar cell. For each wafer, the solar cell with the closest $J_{\mathrm{sc}}$ value to the median of the five cells, was chosen for the EQE measurement. TCO sheet resistance $\left(R_{\text {sheet }}\right)$ was measured using a transfer length method (TLM) structure screen-printed simultaneously with the front silver grid.

Raman spectra of nc-Si:H layers were acquired directly on the wafer on areas uncovered by TCO. To avoid the contribution of the c-Si and the a-Si:H(i) layer underneath, a $325 \mathrm{~nm}$ UV laser was used to probe only the top $10-15 \mathrm{~nm}$ of the layers [35]. To obtain an accurate background shape and extract the crystalline and amorphous phase features, Raman spectra were fitted with Gaussians centered around 315, 420, $480,510,520$ and $625 \mathrm{~cm}^{-1}$ [36]. The Raman crystallinity $\left(X_{c}\right)$ is then computed as $\mathrm{X}_{e}=\frac{A_{510}+A_{520}}{A_{480}+A_{510}+A_{520}}$ were the A's are the amplitudes of the respective amorphous and crystalline Gaussians [37].

Finally, using a $442 \mathrm{~nm}$ laser with a probing depth down to the wafer, we used the c-Si signal counts attenuation to measure the absorption of the ip stack at this wavelength, as was used in [38].

\section{Characterization on reference layers}

Dark conductivity samples were prepared by co-depositing ip stacks on glass substrates and then evaporating $~ 100 \mathrm{~nm}$ thick Al pads at room temperature. The samples were then placed in an $\mathrm{N}_{2}$ atmosphere of approximately 1 mbar on a thermally conductive chuck. The temperature was ramped from $25{ }^{\circ} \mathrm{C}$ to $180{ }^{\circ} \mathrm{C}$ in $15 \mathrm{~min}$, held for $90 \mathrm{~min}$, and then ramped down to $25{ }^{\circ} \mathrm{C}$ during 4 hours. The resistance between the two pads was measured using two-probe pogo-pins on each pad and electrometers. The activation energy of the dark lateral conductivity $\left(E_{A}\right)$ and room temperature conductivity $\left(\sigma_{R T}\right)$ were calculated on the descending temperature range, by fitting the data between $30{ }^{\circ} \mathrm{C}$ to $145{ }^{\circ} \mathrm{C}$ with the formula $\sigma(T)$ $=\sigma_{0} \exp \left(-E_{A} / k T\right)$, with $\mathrm{k}$ being the Boltzmann factor and $\sigma_{0} \mathrm{a}$ pre-factor equal to the extrapolated conductivity at infinite temperature. Different pre-treatments were applied before the Al pads evaporation, as shown in the Appendix.

Transmission electron microscopy (TEM) was performed to assess the overall microstructure. A TMB-based c-Si(n)/a$\mathrm{Si}: \mathrm{H}(\mathrm{i}) / \mathrm{SiO}_{x} / \mathrm{nc}-\mathrm{Si}: \mathrm{H}(\mathrm{p})$ stack (flow of TMB of $9.5 \mathrm{sccm}$ ) was deposited on a mechanically polished (111) c-Si wafer and the TEM sample was prepared using the conventional focused ion beam lift-out method in a Zeiss NVision 40 dual beam FIB/scanning electron microscopy system. The lamella was then analyzed by TEM in a double Cs-corrected TFS Titan Themis operated at $200 \mathrm{kV}$. Scanning TEM (STEM) highangle annular dark-field images and corresponding energydispersive X-ray spectroscopy maps were acquired with a beam current of $400 \mathrm{pA}$.

The thicknesses of the layers were measured using variableangle spectroscopic ellipsometry from co-deposited ip stacks on glass substrates. Spectrums were acquired in the range 1.5$6 \mathrm{eV}$ at angles of $50^{\circ}, 60^{\circ}$ and $80^{\circ}$ using a Horiba Jobin Yvon ellipsometer. Modeling was performed in the DeltaPsi2 software as follows. First, a standard a-Si:H(i) layer was characterized and fitted to a single Tauc-Lorentz (TL) model, yielding a layer thickness of around $8 \mathrm{~nm}$. The nc-Si:H(p) layers in the ip stacks were modeled as a double TL with peak at $3.36 \mathrm{eV}$ and $4.25 \mathrm{eV}$, as suggested in Ref. [39]. Finally, surface roughness was added. Note that modeling the nc-Si with a single TL or otherwise with a double TL and an additional Harmonic Oscillator and testing various starting conditions gave similar thicknesses as those reported here.

Finally, the chemical composition along the ip stack depth was characterized via Secondary Ion Mass Spectrometry (SIMS) measurements performed on a double-side polished (111) n-type wafer. A CAMECA SC-Ultra instrument operating with a $\mathrm{Cs}^{+}$or $\mathrm{O}_{2}{ }^{+}$bombardment at a low impact energy $(1 \mathrm{keV})$ was used. Secondary ions were collected from an area of $60 \mu \mathrm{m}$ in diameter and analyzed in different conditions to optimize the ionization yield of the elements of interest. Boron was analyzed as $\mathrm{B}^{+}$, whereas fluorine and oxygen were analyzed as negative ions $\left(\mathrm{F}^{-}\right.$and $\mathrm{O}^{-}$respectively) 
Publisher version:

10.1109/JPHOTOV.2021.3074072

at high mass resolution (2000). Silicon and hydrogen were
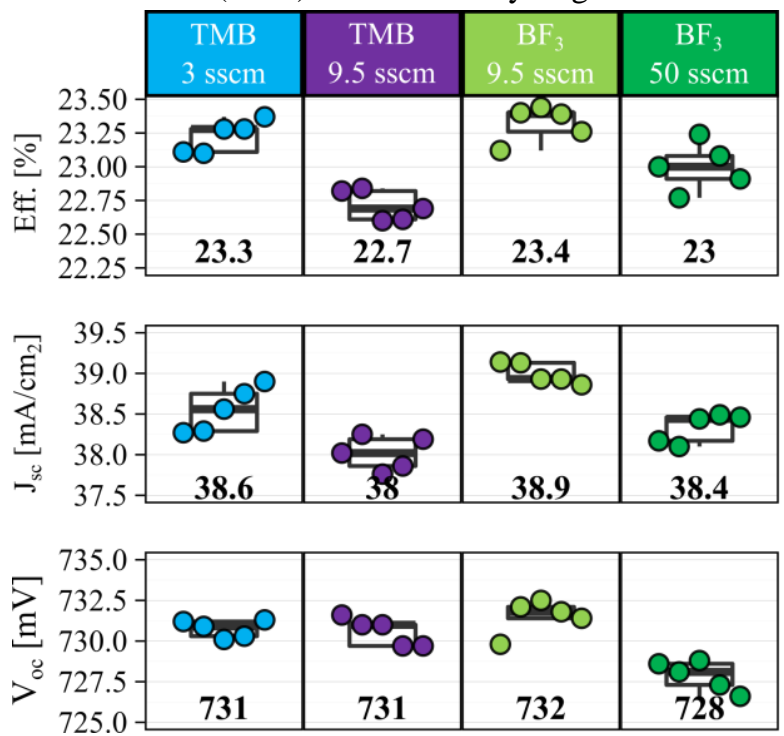

collected as $\mathrm{SiCs}^{+}$and $\mathrm{HCs}_{2}{ }^{+}$ions, respectively.
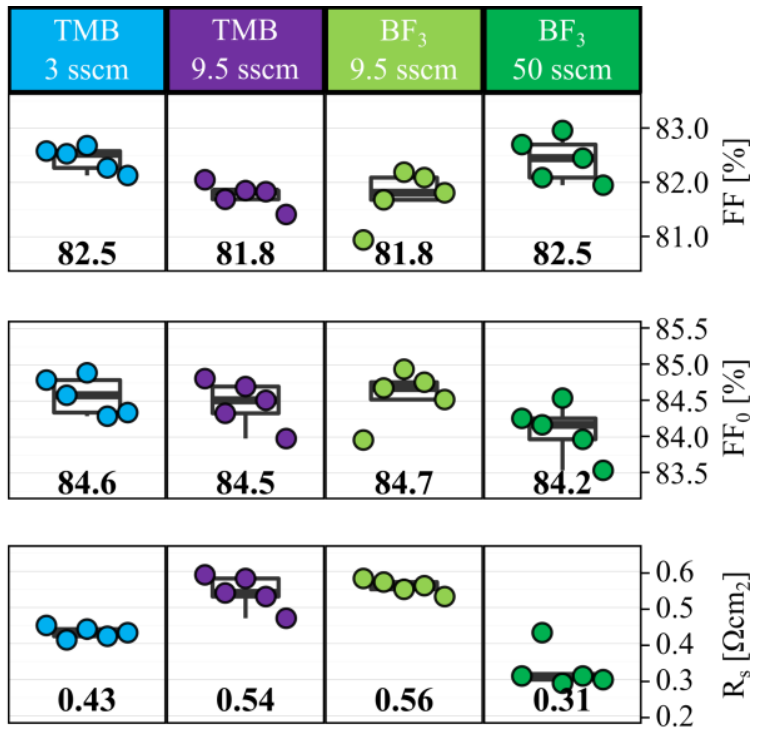

Figure 2. IV characteristics for the samples of the " TMB and BF3 doping series" (after deposition of the SiOx DARC).

a)

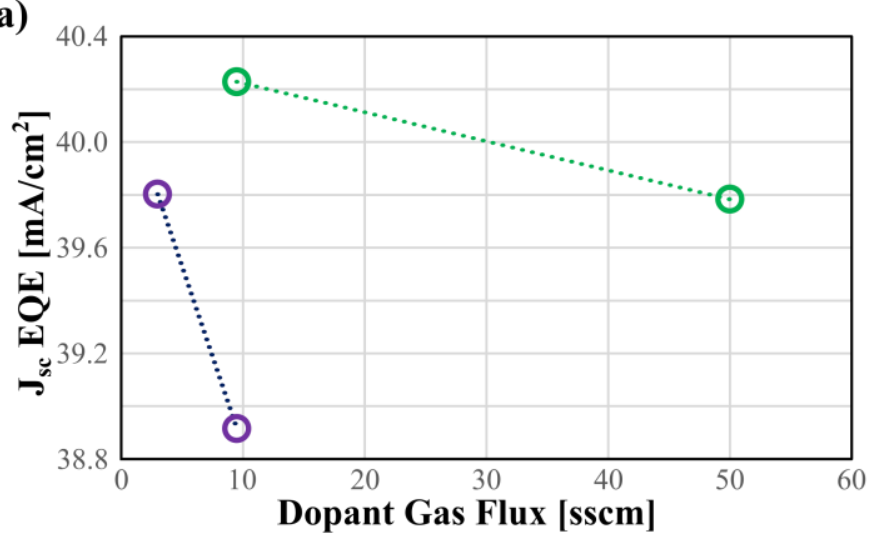

c)

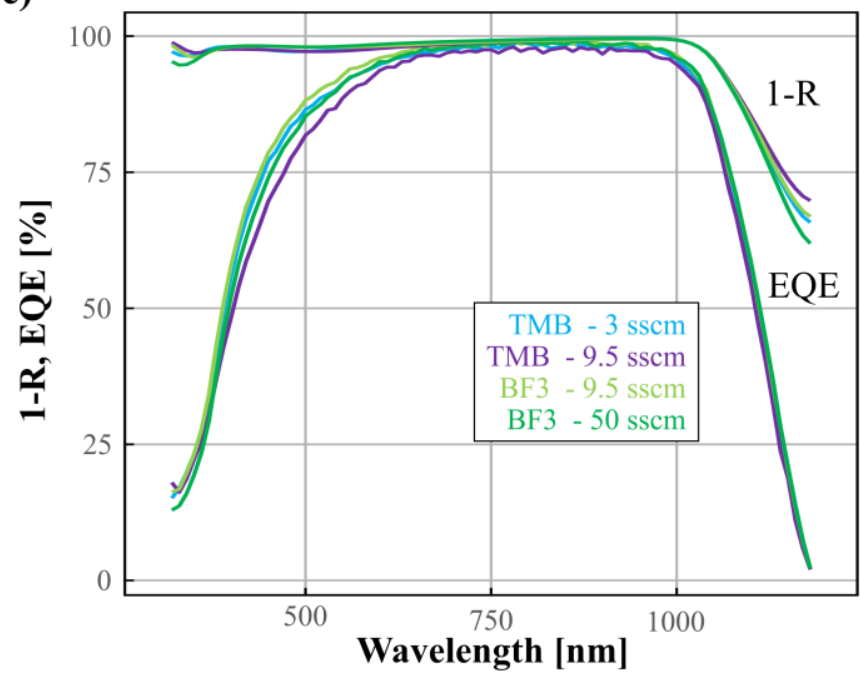

b)

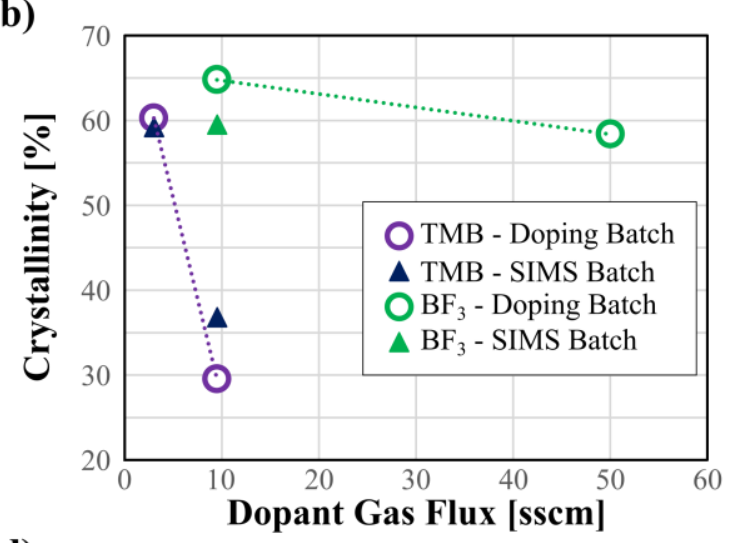

d)

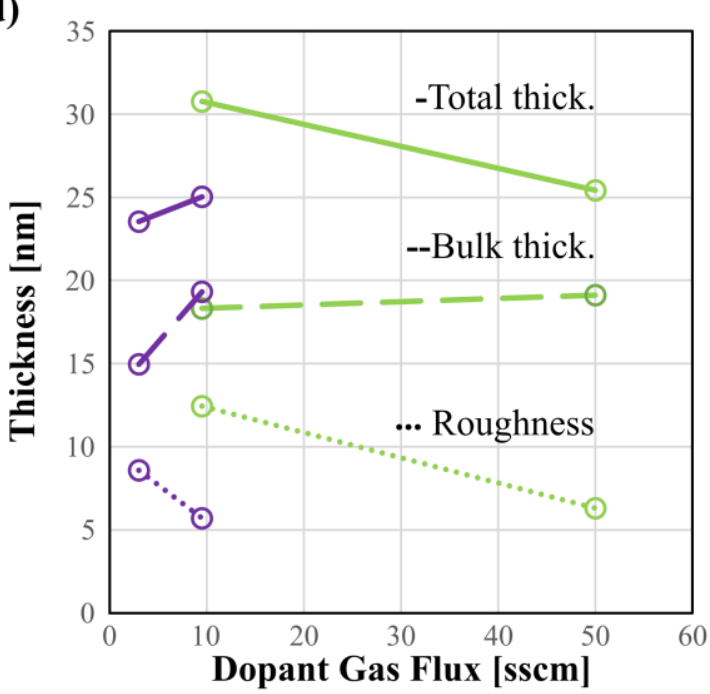

Figure 3. Analysis of the optical properties of the "TMB and BF3 doping series". (a) Short-circuit current integrated from the convolution of EQE with AM1.5G. (b) Raman crystallinity for two different batches. (c) EQE and reflectance (displayed as 1-R) of the solar cell. (d) Thicknesses obtained from ellipsometry, with Total thick. $=$ Bulk thick + Roughness. 
Publisher version:

10.1109/JPHOTOV.2021.3074072

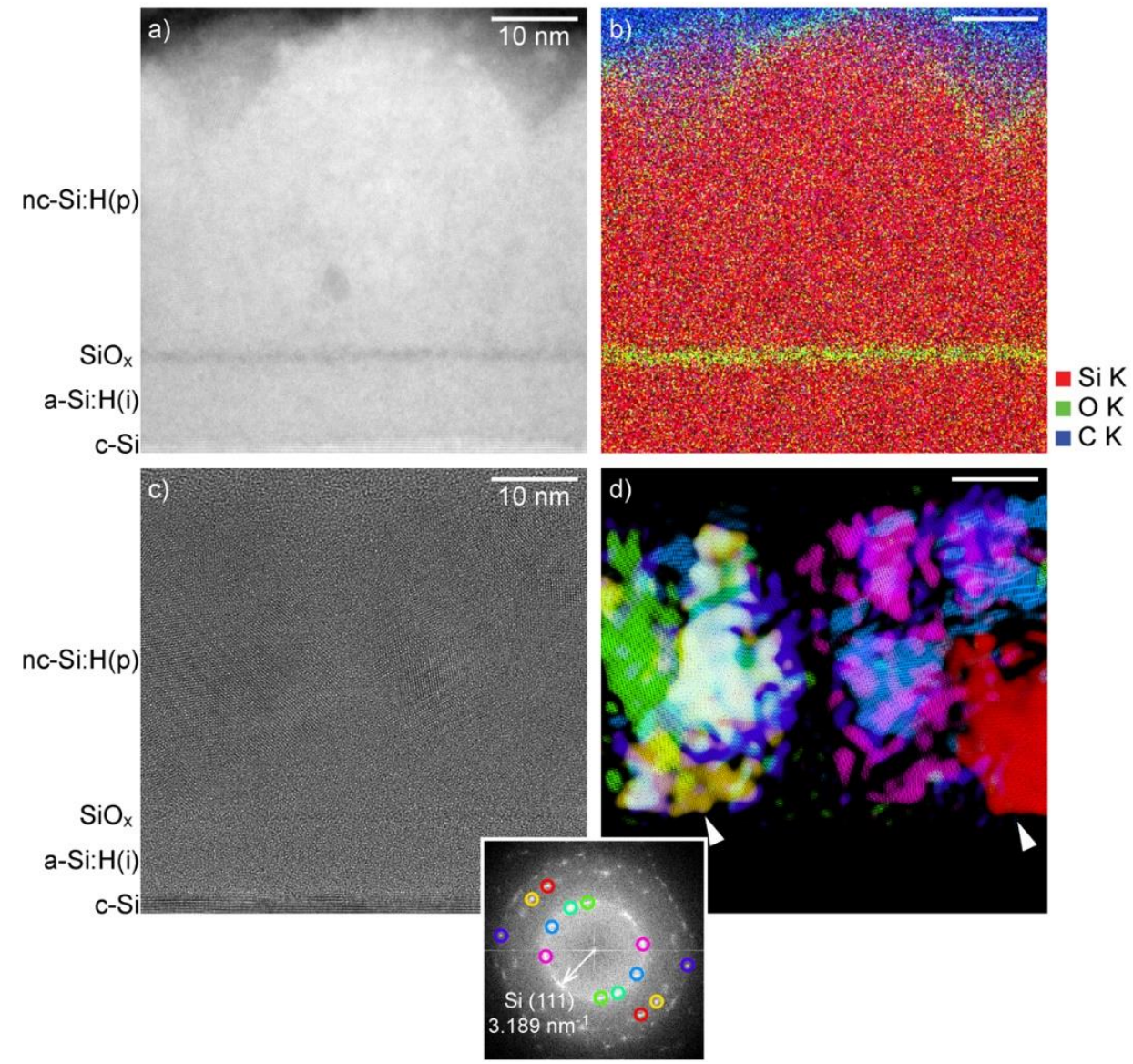

Figure 4. a) STEM HAADF image of the c-Si(n) / a-Si:H(i) / SiOx / nc-Si:H(p) stack, b) corresponding net EDX intensity map of the Si, O and C K edges, c) high-resolution TEM images and d) corresponding inverse Fourier transform of a selection of Si reflections (Fourier transform provided as inset).

(a)

- TMB - Doping Batch

$\mathrm{BF}_{3}$ - Doping Batch

$\Delta$ TMB - SIMS Batch

$\Delta \mathrm{BF}_{3}$ - SIMS Batch

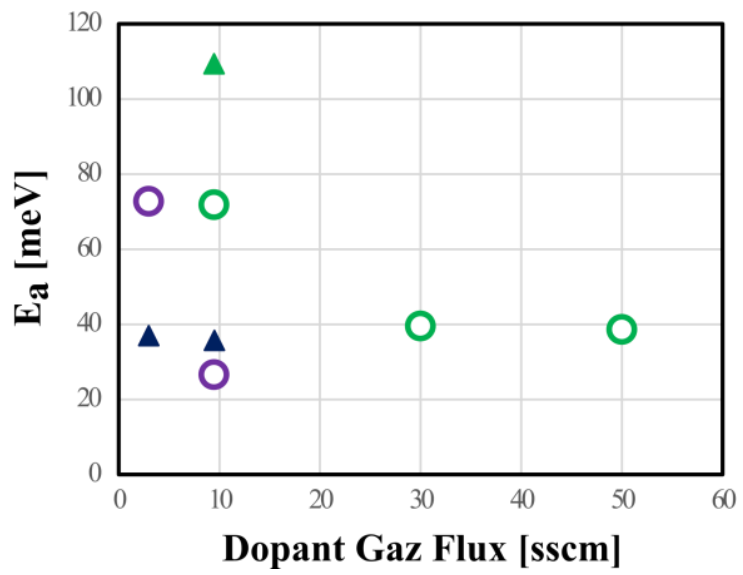

(b)

\section{SIMS Boron doping profile}

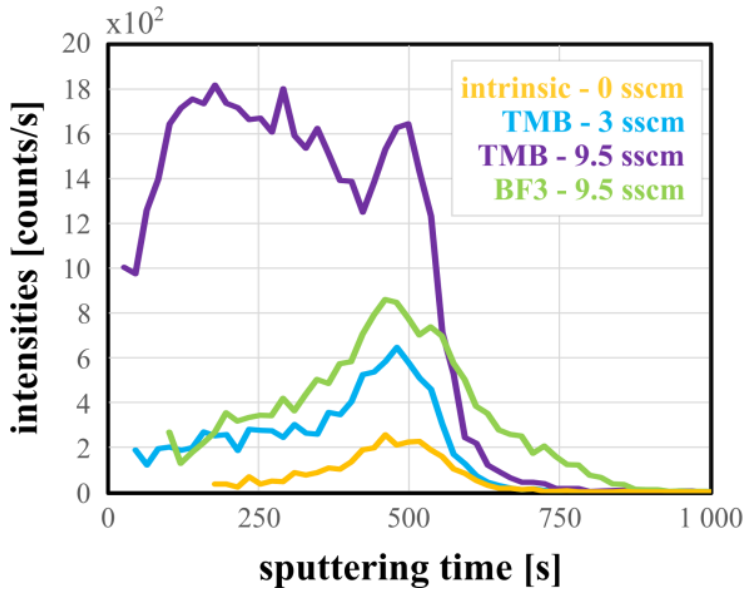

Figure 5. (a) Activation energy of the BF3- and TMB- prepared nc-Si:H(p) layers for different dopant flows and two different batches of samples. (b) SIMS Boron profile of ip stacks deposited on DSP wafer. 


\section{RESULTS AND DISCUSSION}

\section{A. TMB and $\mathrm{BF}_{3}$ doping series}

\section{1) $I V$}

The IV results for the "TMB and $\mathrm{BF}_{3}$ doping series" are presented in Figure 2. We will first describe here only the impact of the used dopant flow upon them, and discuss the relation to the material properties more in depth in the next sections. We observe that efficiency values close to $23.5 \%$ can be obtained both with $\mathrm{TMB}$ and $\mathrm{BF}_{3}$. All devices feature high $\mathrm{V}_{\mathrm{oc}}$ above $730 \mathrm{mV}$, except for the $50 \mathrm{sccm} \mathrm{BF}_{3}$ flow, for which it is slightly lower of $2 \mathrm{mV}$ and a $0.5 \%$ drop of the median FF0 is also noticeable. This sample might suffer from a slightly lower passivation quality, as can be seen from the lifetime measurement of the solar cell precursor (given in the Appendix), possibly due to a longer waiting time before processing the a-Si:H(i) front layer, which was observed in previous experiments (not shown here) to negatively impact passivation. Despite this small passivation issue, increasing the $\mathrm{BF}_{3}$ flow from 9.5 to $50 \mathrm{sccm}$ allows reducing the series resistance of $\sim 0.2 \Omega \mathrm{cm}^{2}$, pushing the FF up to $83 \%$ for the best cell. Yet, it also leads a drop in the median Jsc of 0.5 $\mathrm{mA} / \mathrm{cm} 2$, which we will discuss in detail in the section below.

Then, comparing $\mathrm{TMB}$ and $\mathrm{BF}_{3}$ with the same flow of 9.5 sccm, we observe a large difference in $J_{S C}$ of about $1 \mathrm{~mA} / \mathrm{cm}^{2}$, while the transport and passivation are very similar (same Voc, FF, FF0 and Rs). Finally, reducing the TMB flow from 9.5 to $3 \mathrm{sccm}$, we observe an increase of the median $J_{S C}$ of $0.6 \mathrm{~mA} / \mathrm{cm}^{2}$ and an improvement of the median $\mathrm{FF}$ of $0.7 \%$ through a reduction of the median Rs of $0.11 \mathrm{~m} \Omega \mathrm{cm}^{2}$. These improvements might come from the enhanced crystallinity of the layer, as discussed in the next sections.

\section{2) Optical and material properties}

Figure 3 presents the data relative to the optical properties of the "TMB and $\mathrm{BF}_{3}$ doping series". We find again the same trend for the $\mathrm{J}_{\mathrm{sc}}$ integrated from EQE than the one from IV measurements. We also observe a clear correlation of the latter with the evolution of the crystallinity. Moreover, this observation is well reproduced among the different batches of this study. The EQE spectrums show that the current difference is happening in the UV-Blue part of the spectrum. Since the difference of reflectance among the samples is too low to explain the EQE trends in the range $320-600 \mathrm{~nm}$, we can conclude to a parasitic absorption phenomenon. Finally, we also note a lower EQE also in the range $600-1180 \mathrm{~nm}$ for the layer prepared with $9.5 \mathrm{sccm}$ of TMB. However, this difference can be ascribed to a more absorbing TCO, as shown by the lower $R_{\text {sheet }}$ (see Figure 8) and lower IR-reflectance (due to more absorption) of this sample.
Ellipsometry measurements show that all p-layers have similar total thicknesses (bulk + roughness) around $25-30 \mathrm{~nm}$, with the small trend visible uncorrelated with the $J_{s c}$ trends. These observations indicate that for the TMB samples, the transparency is controlled by the Raman crystallinity of the sample, a change of crystallinity from $60 \%$ to $30 \%$ leading to a drop of $J_{\text {sc }}$ of $0.6 \mathrm{~mA} / \mathrm{cm}^{2}$ in the range $320-600 \mathrm{~nm}$ of the spectrum. This is expected due to the higher absorption of the amorphous phase compared to the crystalline one.

However, the phenomenon is different for $\mathrm{BF}_{3}$. Contrary to $\mathrm{TMB}, \mathrm{BF}_{3}$ does not strongly hinder the crystallization, either due to the absence of carbon [40] or lower boron incorporation [23], and only a small drop of crystallinity of $5 \%$ is observed when going from 9.5 to $50 \mathrm{sccm}$. However, despite this small change, we observe a significant $J_{\mathrm{sc}}$ drop of $0.4 \mathrm{~mA} / \mathrm{cm}^{2}$. Further discussion on this absorption is provided in the " $\mathrm{BF}_{3}$ doped layer thickness series" section.

Completing the observation of the structural properties, TEM analysis was performed on the full c-Si(n) / a-Si:H(i) / $\mathrm{SiOx} / \mathrm{nc}-\mathrm{Si}: \mathrm{H}(\mathrm{p})$ stack with the $9.5 \mathrm{sccm}$ TMB recipe which leads to the lower crystallinity among the layer presented in this study, however with a deposition time longer of $33 \%$ (see Figure 4). The total thickness of the full c-Si(n) / a-Si:H(i) / $\mathrm{SiOx} / \mathrm{nc}-\mathrm{Si}: \mathrm{H}(\mathrm{p})$ stack thickness approaches $40 \mathrm{~nm}$, including a roughness in the order of $10 \mathrm{~nm}$. This corresponds to results given by ellipsometry, taking into account the longer deposition time of this layer. The STEM EDX map and the inverse Fourier transforms of a selection of $\mathrm{Si}$ reflections computed from a high-resolution TEM image highlight the short nucleation zone of the nanocrystalline phase after the $\mathrm{O}$ rich layer. Thanks to the $\mathrm{SiO}_{\mathrm{x}}$ pre-treatment [18] and the substrate temperature lower than $200{ }^{\circ} \mathrm{C}$ [19], the Si crystalline domains do not exhibit the typically conical shape [41] but instead nucleate with a large cross-section already during the early stages of the growth (see arrowheads), and this already for the less crystalline layer recipe.

\section{3) Transport, activation energy, and boron content}

Figure 5 a) presents the dark conductivity activation energy $\left(E_{A}\right)$ of the a-Si:H(i) / nc-Si:H(p) stacks co-deposited on glass substrate. With a $9.5 \mathrm{sccm}$ of dopant gas flow, the sample prepared with TMB systematically exhibits the lowest $E_{A}(\sim 30$ $\mathrm{meV})$ compared to the one prepared using $\mathrm{BF}_{3}(\sim 70 \mathrm{meV}$ or higher depending on the batch considered). However, the high $E_{A}$ of $\mathrm{BF}_{3}$ layers can be reduced to $\sim 30 \mathrm{meV}$ as well by increasing the dopant flow. Finally, we can see that by reducing the TMB flow to $3 \mathrm{sccm}$, we can still reach a low $E_{A}$ of $\sim 30 \mathrm{meV}$. However, this latter observation was not reproducible systematically, as can be seen by the differences 
between the "TMB and $\mathrm{BF}_{3}$ doping series" and the "SIMS batch" and is discussed at the end of this section.

Correlating the $E_{a}$ of Figure 5 a) with the crystallinity of Figure 3 b), we observe that a low activation energy is not always correlated with a high crystallinity. In the case of $\mathrm{BF}_{3}$, both flows lead to similar crystallinities and increasing the dopant flow only decreases $E_{A}$, suggesting an increase of doping due to the higher flow of dopant precursor. On the other hand, layers doped with $3 \mathrm{sccm}$ of TMB show a high crystallinity, but the $\mathrm{B}$ concentration in the film might be too low to reach a high doping, leading to a higher $\mathrm{E}_{\mathrm{A}}$ than for larger TMB flows even though the latter have a lower crystallinity.

In Figure 5 b), we see that the higher TMB flow of 9.5 sccm yields a higher B content in the layer as expected. The intrinsic reference also shows a small B amount, probably due to the chamber's contamination by the preceding p-layer deposition. Finally, the lower TMB flow of $3 \mathrm{sccm}$ and the 9.5 sccm $\mathrm{BF}_{3}$ layer show similar $\mathrm{B}$ contents, possibly due to the lower dissociation of $\mathrm{BF}_{3}$ in the plasma [24].

Considering the "SIMS Batch" characterization, we can therefore conclude that for TMB, even a low B incorporation can lead to a layer with a low $E_{A}$, possibly explained by a better dopant activation in this more crystalline layer. Even though the 3 sccm TMB sample's activation energy is higher than for $9.5 \mathrm{sccm}$ for the "TMB and $\mathrm{BF}_{3}$ doping series", this translates into a better series resistance for the solar cell. The $E_{A}$ observed for the layer doped with $9.5 \mathrm{sccm}$ of $\mathrm{BF}_{3}$ in the SIMS batch is intriguingly much higher than the one of the 3 sccm TMB sample despite similar B concentration. This could suggest that some $\mathrm{B}$ is inactive when $\mathrm{BF}_{3}$ is used. e.g. due to an incorporation as dopant-inactive $\mathrm{BF}_{\mathrm{X}}$-groups.

The lack of correlation between the series resistance of the solar cell and the layers' dark conductivity activation energy could be explained by the following facts. First, we are looking at very small variations in the activation energy and series resistance. Second, the trends might be lower than batch-tobatch variations. Indeed, simulations of IBC-SHJ of the transport through the i-p-TCO hetero-interface and subgap energy states showed that all activation energies lower than $100 \mathrm{meV}$ and a TCO doping higher than $10^{20} \mathrm{~cm}^{-3}$ enable reaching similar values of FF [43], which is the case here. Third, a low flow of $3 \mathrm{sccm}$ of TMB is actually close to the mass flow controller minimal value, which can explain the variability of the activation energy. Finally, note that the accurate measurement of the activation energy in the small range between 30 to $100 \mathrm{meV}$ can also depend on the sample preparation, as shown in the Appendix. 
Publisher version:

10.1109/JPHOTOV.2021.3074072

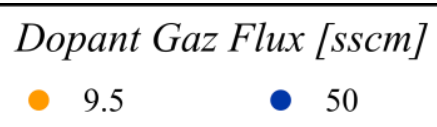

\section{Doped Chamber + Holder plate Coating}

$\mathrm{BF}_{3} 50 \mathrm{sscm}$ 3:30

$\mathrm{BF}_{3}$ 9,5 sscm 3:30

TMB 9,5 sscm 3:30
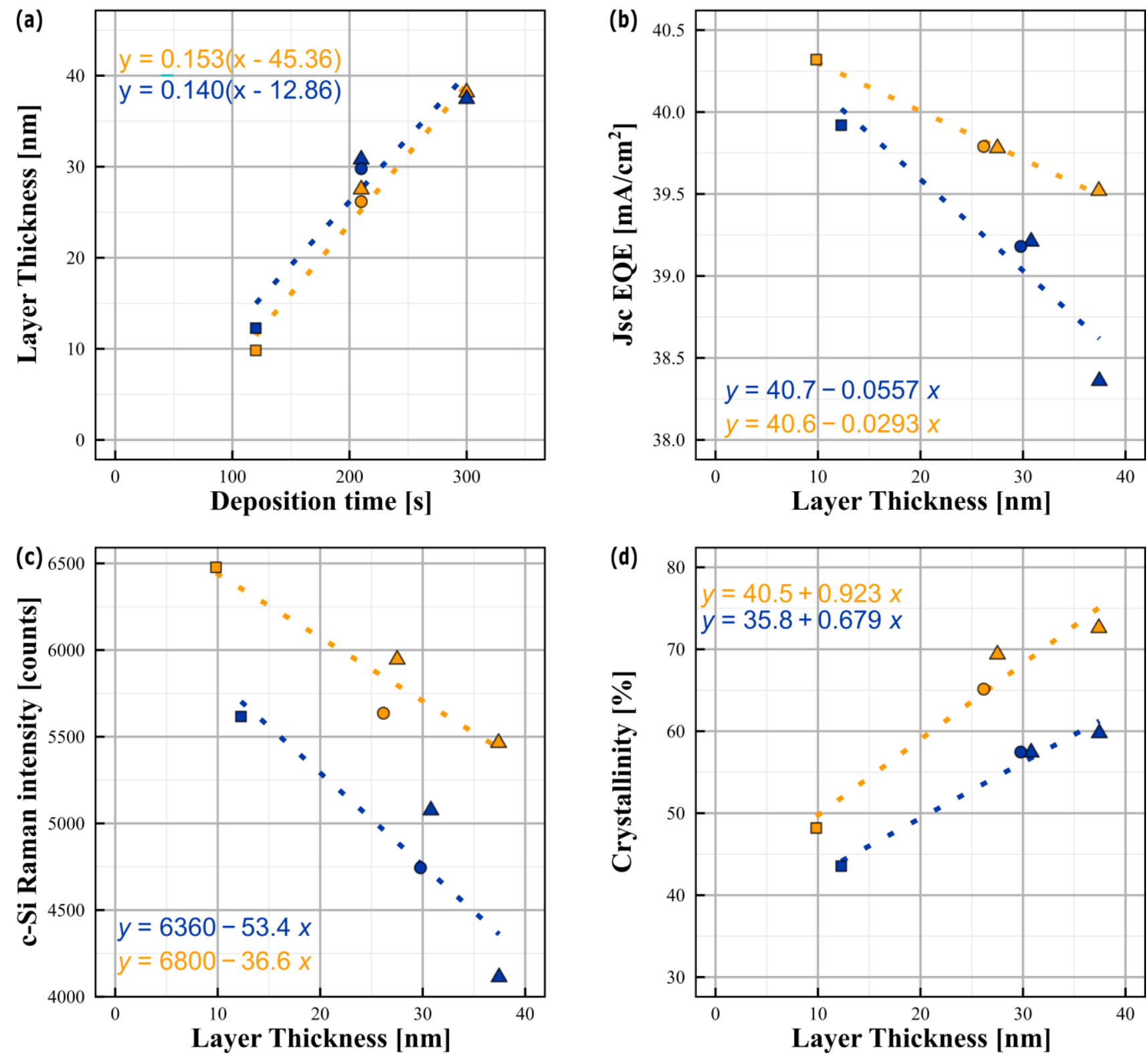

Figure 6. Analysis of the optical properties of BF3-doped p-layer. (a) Total layer thickness (bulk + roughness) measured by ellipsometry v.s. deposition time of the p-layer. (b) Current integrated from EQE, (c) Raman signal from the underneath c-Si Wafer measured with a 442nm laser wavelength vs. p-layer thickness and (d) Crystallinity of the p-layer.

\section{B. $\quad B_{3}$-doped layer thickness series}

To clarify the absorption of $\mathrm{BF}_{3}$-doped layers, we processed p-layers with 9.5 and $50 \mathrm{sccm}$ of $\mathrm{BF}_{3}$ and varied their deposition time. Moreover we varied the chamber coating prior to the ip stack deposition to detect a possible influence from the plate coating on the i-layer properties when using a high dopant flow, as explained in the experimental part. Figure 6 presents the results of this study.

The layers have similar thicknesses, low deposition rates of $0.14-0.15 \mathrm{~nm} / \mathrm{s}$, and layers start to grow after a delayed of 10$50 \mathrm{~s}$ which could correspond to the nucleation time [24]. For 
$210 \mathrm{~s}$, which is the same deposition time as the "TMB and $\mathrm{BF}_{3}$ doping series", we find similar p-layer thicknesses between 25 to $30 \mathrm{~nm}$ and confirm a current drop of $\sim 0.4-0.5 \mathrm{~mA} / \mathrm{cm}^{2}$ when going from 9.5 to $50 \mathrm{sccm}$. Looking at the dependence of $\mathrm{J}_{\mathrm{sc}}$ upon thickness, we notice that using $50 \mathrm{sccm}$ of $\mathrm{BF}_{3}$ always leads to higher absorption. This data shows a similar value of current of $40.6-40.7 \mathrm{~mA} / \mathrm{cm}^{2}$ extrapolated for a zero nm-thick layer and almost a twice as large slope for $50 \mathrm{sccm}$ compared to $9.5 \mathrm{sccm}$ with a current loss of 0.06 and 0.03 $\mathrm{mA} / \mathrm{cm}^{2} / \mathrm{nm}$ respectively. This factor of two between the slopes is also reproduced using Raman profilometry [33] as shown in Figure 6 d). These observations, correlating multiple samples, confirm that layers prepared with $50 \mathrm{sccm}$ of $\mathrm{BF}_{3}$ absorb more than those prepared with $9.5 \mathrm{sccm}$, without any noticeable influence from the chamber coating.

Regarding structural properties, the crystallinity measurements show that using a $50 \mathrm{sccm}$ flow instead of 9.5 sccm slows down slightly the crystallite growth, similarly to [23] yet less strongly. The offset is up to $10-12 \%$ for $\sim 40 \mathrm{~nm}$ layers, whereas it tends towards less than $5 \%$ for a zero thickness. Thus, since the difference is increasing with the growth, we conclude that this effect stems from a bulk modification of the nanocrystalline layer and not its incubation zone. More in-depth characterizations on the boron content, layer porosity and the grain size would be needed to confirm these theories.

\section{RECORD CELL AND OUTLOOK}

In the previous section, we showed possible to combine high $J_{\mathrm{sc}}$ and FF by using p layers prepared with low TMB flows. As an illustration of the potential of this layer, we produced a $2 \times 2 \mathrm{~cm}^{2}$ solar cell with the same structure and processes as for the "TMB and $\mathrm{BF}_{3}$ doping series". Solar cells featured a 4-sccm TMB p-layer, an indium zirconium oxide layer (allowing higher mobility than ITO for same optical properties [28],[29]), a single screen-printing step, finished with a $\sim 100 \mathrm{~nm}$ (on textured wafer) $\mathrm{SiO}_{\mathrm{x}}$ layer (see

Figure 1). A flow of $4 \mathrm{sccm}$ of TMB was used instead of the $3 \mathrm{sccm}$ to avoid using values too close to the minimum of the mass flow controller and allow more reproducible results. A high crystallinity of $67 \%$ was also measured for this sample (not shown), showing that the resulting material properties are similar.

The cells were then held in forward-bias conditions for two weeks to improve their passivation properties [33]. Figure 7 shows the independently certified results, reaching conversion efficiency of $23.92 \%$, a FF of $82.22 \%, J_{\mathrm{sc}}$ value of 39.6 $\mathrm{mA} / \mathrm{cm}^{2}$ and $V_{o c}$ of $734.5 \mathrm{mV}$. From Fig. 2, we can suggest that a similar efficiency could be obtained using a $\mathrm{BF}_{3}$ flow of $9.5 \mathrm{sccm}$. However, changing the $\mathrm{BF}_{3}$ flow does not allow to relax the trade-off between transparency and transport, since it increases more the parasitic absorption than it decreases the series resistance.

For TMB p-layers, it has been shown that higher efficiencies up to $24.1 \%$ can be obtained by alloying the layer with oxygen in a multilayer approach [32]. Higher efficiency could be obtained then by optimizing the $\mathrm{i}$ - and p-layer thicknesses. For the $\mathrm{BF}_{3}$ p-layers, the very low series resistance achieved despite stronger absorption in the UV could be of interest for rear-junction application. Moreover, the integration of $\mathrm{nc}-\mathrm{Si}: \mathrm{H}$ in industrial production is still a challenge due to the low deposition rate. Since $\mathrm{BF}_{3}$ is less sensitive than TMB to amorphization of the layer, a less dilute

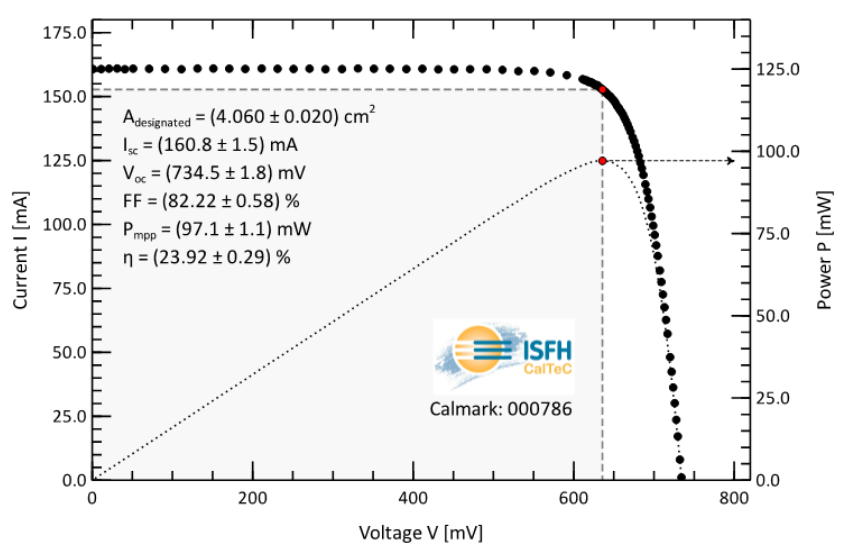

Figure 7. IV certification of the optimize device featuring the $4 \mathrm{sccm}$ TMB front nc-Si:H(p) layer. regime could be explored to reach faster deposition rates.

\section{CONCLUSION}

We investigated the influence of $\mathrm{TMB}$ and $\mathrm{BF}_{3}$ as dopant sources on the transparency, contact properties of nc-Si:H(p) layers and their integration in solar cells. Both gas precursors allow to reach high efficiencies. Reaching a FF above $82 \%$ is possible by lowering the dark conductivity activation energy of the layers down to $30 \mathrm{meV}$. A high $J_{\mathrm{sc}}$ can be obtained by increasing the crystallinity to $60 \%$. Overall, it is possible to reach both a low $E_{A}$ and a high crystallinity with a low TMB flow. Based on these findings, the TMB nc-Si:H(p) layer's potential was illustrated by presenting a certified $23.9 \%$ efficient solar cell featuring a $100 \mathrm{~nm}$ DARC SiOx layer. Then, we showed that it is possible to reach slightly higher crystallinity and current by switching from TMB to $\mathrm{BF}_{3}$ as the dopant source, however at the expense of a higher $E_{A}$. A higher dopant-gas flow was needed to reach similar $E_{A}$ values, which induces parasitic absorption in the UV and precludes a clear benefit to be seen by using $\mathrm{BF}_{3}$ or TMB. This parasitic absorption was shown be not linked to a difference in crystallinity or thickness and it remains to be fully explained. 
The use of $\mathrm{BF}_{3}$ remains of specific interest in rear junction configuration since the optical drawbacks are then alleviated, and the electrical benefits would be maintained.

\section{ACKNOWLEDGMENT}

The authors would like to thank C. Allebé and P. Wyss for the wafer cleaning and texturization, V. Paratte for SHJ baseline processes survey, N. Badel for the silver screenprinting metallization, M. Lehmann and P. Fiala for the routine calibration of the IV setup, L.-L. Senaud for examination of the dark conductivity data and setup, and finally C. Bucher and A. Schafflützel for technical support.

\section{REFERENCES}

D. Adachi, J. L. Hernández, and K. Yamamoto, "Impact of carrier recombination on fill factor for large area heterojunction crystalline silicon solar cell with $25.1 \%$ efficiency," Appl. Phys. Lett., vol. 107, no. 23 , pp. $1-4,2015$.

[2] X. Ru et al., " $25.11 \%$ Efficiency Silicon Heterojunction Solar Cell With Low Deposition Rate Intrinsic Amorphous Silicon Buffer Layers," Sol. Energy Mater. Sol. Cells, vol. 215, no. June, p. $110643,2020$.

[3] K. Yoshikawa et al., "Silicon heterojunction solar cell with interdigitated back contacts for a photoconversion efficiency over 26\%," Nat. Energy, vol. 2, no. 5, 2017.

[4] J. Zhao, T. Xie, and R. Zhou, " $>24 \%$ Silicon Heterojunction Solar Cells on Meyer Burger's Mass Production Tools and How Wafer Material Impacts Cell Parameters," 2018.

[5] D. Chen et al., "Defect engineering of p-type silicon heterojunction solar cells fabricated using commercial-grade low-lifetime silicon wafers," Prog. Photovoltaics Res. Appl., no. December 2018, pp. $1-15,2019$.

[6] Commissariat à l'énergie atomique et aux énergies alternatives (CEA), "25\%!!! New world-class certified record for heterojunction solar cell efficiency." [Online]. Available: https://www.cea.fr/ceatech/liten/english/Pages/Medias/News/PV-High-Efficiency/25New-world-class-certified-record-for-heterojunction-solar-cellefficiency-.aspx. [Accessed: 25-Jan-2021].

[7] Z. C. Holman et al., "Current Losses at the Front of Silicon Heterojunction Solar Cells," IEEE J. Photovoltaics, 2014.

[8] A. Shah, Thin-film silicon solar cells. CRC Press, 2010.

[9] M. Bivour, S. Schröer, and M. Hermle, "Numerical analysis of electrical TCO / a-Si:H(p) contact properties for silicon heterojunction solar cells," Energy Procedia, vol. 38, pp. 658-669, 2013.

[10] J. P. Seif et al., "Strategies for Doped Nanocrystalline Silicon Integration in Silicon Heterojunction Solar Cells," IEEE J. Photovoltaics, vol. 6, no. 5, pp. 1132-1140, 2016.

[11] A. Tomasi et al., "Simple processing of back-contacted silicon heterojunction solar cells using selective-area crystalline growth," Nat. Energy, vol. 2, no. 5, pp. 1-8, 2017.

[12] T. Watahiki et al., "Rear-emitter Si heterojunction solar cells with over 23\% efficiency," Appl. Phys. Express, vol. 8, no. 2, p. 021402 , 2015.

[13] L. Mazzarella, A. B. Morales-Vilches, L. Korte, R. Schlatmann, and B. Stannowski, "Ultra-thin nanocrystalline n-type silicon oxide front contact layers for rear-emitter silicon heterojunction solar cells," Sol. Energy Mater. Sol. Cells, vol. 179, no. January, pp. 386-391, 2018.

[14] L. Mazzarella et al., "Nanocrystalline n-type silicon oxide front contacts for silicon heterojunction solar cells: Photocurrent enhancement on planar and textured substrates," IEEE J. Photovoltaics, vol. 8, no. 1, pp. 70-78, 2018.

[15] L. Mazzarella, S. Kirner, B. Stannowski, L. Korte, B. Rech, and R. Schlatmann, "P-type microcrystalline silicon oxide emitter for silicon heterojunction solar cells allowing current densities above
$40 \mathrm{~mA} / \mathrm{cm} 2$, , Appl. Phys. Lett., vol. 106, no. 2, 2015.

[16] Y. Zhao et al., "Doped hydrogenated nanocrystalline silicon oxide layers for high-efficiency c-Si heterojunction solar cells," Prog. Photovoltaics Res. Appl., no. February, pp. 1-11, 2020.

[17] J. Haschke, O. Dupré, M. Boccard, and C. Ballif, "Silicon heterojunction solar cells: Recent technological development and practical aspects - from lab to industry," Sol. Energy Mater. Sol. Cells, vol. 187, no. July, pp. 140-153, 2018.

[18] M. Boccard, R. Monnard, A. N. Fioretti, L. Antognini, and C. Ballif, "Silicon Oxide Treatment to Promote Crystallinity of p-type Microcrystalline Layers for Silicon Heterojunction Solar Cells," Proc. SiliconPV2018, AIP, 2018.

[19] A. N. Fioretti, M. Boccard, R. Monnard, and C. Ballif, "LowTemperature p-Type Microcrystalline Silicon as Carrier Selective Contact for Silicon Heterojunction Solar Cells," IEEE J. Photovoltaics, vol. PP, pp. 1-8, 2019.

[20] J. Haschke, G. Christmann, C. Messmer, M. Bivour, M. Boccard, and C. Ballif, "Lateral transport in silicon solar cells," J. Appl. Phys., vol. 127, no. 11, 2020.

[21] A. Cruz et al., "Influence of Silicon Layers on the Growth of ITO and AZO in Silicon Heterojunction Solar Cells," IEEE J. Photovoltaics, vol. PP, pp. 1-7, 2019.

[22] A. Hadjadj, N. Pham, P. Roca I Cabarrocas, O. Jbara, and G. Djellouli, "Ellipsometry investigation of the amorphous-tomicrocrystalline transition in a-Si:H under hydrogen-plasma treatment," J. Appl. Phys., vol. 107, no. 8, 2010.

[23] L. Guo et al., "Nanostructure, electrical and optical properties of ptype hydrogenated nanocrystalline silicon films," Vacuum, vol. 85, no. 6, pp. 649-653, 2011.

[24] J. Koh, H. Fujiwara, R. J. Koval, C. R. Wronski, and R. W. Collins, "Real time spectroscopic ellipsometry studies of the nucleation and growth of p-type microcrystalline silicon films on amorphous silicon using $\mathrm{B} 2 \mathrm{H} 6, \mathrm{~B}(\mathrm{CH} 3) 3$ and $\mathrm{BF} 3$ dopant source gases," $J$. Appl. Phys., vol. 85, no. 8 I, pp. 4141-4153, 1999.

[25] T. Matsui, M. Kondo, and A. Matsuda, "Doping properties of boron-doped microcrystalline silicon from $\mathrm{B} 2 \mathrm{H} 6$ and $\mathrm{BF} 3$ : Material properties and solar cell performance," J. Non. Cryst. Solids, vol. 338-340, no. 1 SPEC. ISS., pp. 646-650, 2004.

[26] D. S. Philipps and W. Warmuth, "Fraunhofer ISE: Photovoltaics Report, updated: 14 March 2019," Fraunhofer ISE Photovoltaics Report, Updat. 14 March 2019, no. March, 2019.

[27] M. Boccard, R. Monnard, L. Antognini, and C. Ballif, "Silicon oxide treatment to promote crystallinity of p-type microcrystalline layers for silicon heterojunction solar cells," in AIP Conference Proceedings, 2018, vol. 1999.

[28] M. Morales-Masis et al., "Highly Conductive and Broadband Transparent Zr-Doped In2O3 as Front Electrode for Solar Cells," IEEE J. Photovoltaics, vol. 8, no. 5, pp. 1202-1207, 2018.

[29] E. Rucavado et al., "Zr-doped indium oxide electrodes: Annealing and thickness effects on microstructure and carrier transport," Phys. Rev. Mater., vol. 3, no. 8, pp. 1-9, 2019.

[30] S. Y. Herasimenka, W. J. Dauksher, M. Boccard, and S. Bowden, "ITO/SiOx:H stacks for silicon heterojunction solar cells," Sol. Energy Mater. Sol. Cells, vol. 158, pp. 98-101, 2016.

[31] A. Cruz et al., "Effect of front TCO on the performance of rearjunction silicon heterojunction solar cells: Insights from simulations and experiments," Sol. Energy Mater. Sol. Cells, vol. 195, no. October 2018, pp. 339-345, 2019.

[32] M. Boccard et al., "Hole-Selective Front Contact Stack Enabling 24.1\%-Efficient Silicon Heterojunction Solar Cells," vol. 11, no. 1, pp. $9-15,2021$.

[33] J. Cattin, M. Boccard, and C. Ballif, "Characterization of silicon heterojunction solar cells beyond standard test conditions," EPFL, 2020.

[34] S. Bowden and A. Rohatgi, "Rapid and accurate determination of series resistance and fill factor losses in industrial silicon solar cells," 17th Eur. Photovolt. Sol. Energy Conf., 2001.

[35] J. V. Carpenter et al., "Substrate-independent analysis of microcrystalline silicon thin films using UV Raman spectroscopy," Phys. status solidi, 2017.

[36] D. Bermejo and M. Cardona, "Raman scattering in pure and hydrogenated amorphous germanium and silicon," J. Non. Cryst. 
[37]

Solids, vol. 32, pp. 405-419, 1979.

C. Smit, R. A. C. M. M. Van Swaaij, H. Donker, A. M. H. N. Petit, W. M. M. Kessels, and M. C. M. Van de Sanden, "Determining the material structure of microcrystalline silicon from Raman spectra," Journal of Applied Physics. 2003.

[38] M. Ledinský et al., "Profilometry of thin films on rough substrates by Raman spectroscopy,” Sci. Rep., vol. 6, pp. 4-10, 2016.

[39] T. Yuguchi, Y. Kanie, N. Matsuki, and H. Fujiwara, "Complete parameterization of the dielectric function of microcrystalline silicon fabricated by plasma-enhanced chemical vapor deposition," J. Appl. Phys., vol. 111, no. 8, 2012.

[40] J. Cho et al., "Wide-bandgap nanocrystalline silicon-carbon alloys for photovoltaic applications," Sol. Energy Mater. Sol. Cells, vol. 182, no. January, pp. 220-227, 2018.

[41] P. Stradins, C. W. Teplin, and H. M. Branz, "Phase evolution in nanocrystalline silicon films: Hydrogen dilution and the cone kinetics model," Philos. Mag., vol. 89, no. 28-30, pp. 2461-2468, 2009.

[42] J. You, "Synergistic effect of CO 2 and PH 3 on the properties of ntype nanocrystalline silicon oxide prepared by plasma-enhanced chemical vapor deposition," J. Mater. Sci. Mater. Electron., 2020.

[43] P. Procel et al., "The role of heterointerfaces and subgap energy states on transport mechanisms in silicon heterojunction solar cells," Prog. Photovoltaics Res. Appl., vol. 28, no. 9, pp. 935-945, 2020.

\section{APPENDIX}

\section{A. SIMS chemical composition}

To link solar-cell transport performance to layer properties, Figure 10 presents the SIMS profiles of the different chemical elements and the activation energy for layers prepared with the different dopant flows.

Figure 10 a) shows the $\mathrm{Si}, \mathrm{H}, \mathrm{O}, \mathrm{F}, \mathrm{C}$, and $\mathrm{B}$ profiles of a representative sample, allowing to observe the important transitions between the different layers: One can observe two peaks in almost every profile (except for Boron) that are characteristics of the wafer interface and of the SiOx surface treatment.

First, similar oxygen profiles are observed for all samples. On the other hand, carbon profiles show two distinctive peaks at the SiOx interface only for the TMB-prepared samples, showing that the carbon present in the precursor is incorporated mainly at the interface with the seed layer.

Secondly, the presence of fluor can be seen at the wafer interface for all samples. This is due to the initial HF treatment to remove the native oxide. For $\mathrm{BF}_{3}$, a large peak of $\mathrm{F}$ can be seen, fluor being accumulated at the oxide interface. Then, the hydrogen profile reveals a very distinct peak at the oxide and wafer surface for all samples except for $\mathrm{BF}_{3}$ where the peak to valley is attenuated in comparison. This flatter profile could indicate that some hydrogen diffuses more in this sample, yet this would need to be confirmed with other measurements or more extensive statistics. Next, we observed a tailing of the F, $\mathrm{H}$ and $\mathrm{B}$ profiles for $\mathrm{BF}_{3}$ samples into the wafer, suggesting a possible diffusion of those species. However, this last affirmation should be put in contrast with the silicon profile of the $\mathrm{BF}_{3}$ samples, which is less dense near the surface of the wafer, indicating a possibly different porosity of the a$\mathrm{Si}(\mathrm{i}): \mathrm{H} / \mathrm{c}-\mathrm{Si}$ interface. If there is indeed diffusion of $\mathrm{F}, \mathrm{H}$ and $\mathrm{B}$, they are correlated with the particular surface condition of this sample and we cannot conclude that this is only an effect triggered in $\mathrm{BF}_{3}$-prepared samples.

\section{B. Activation energy influence on samples treatments}

In this section, we present the effect of sample treatments upon the measured activation energy $E_{A}$. Different treatments were applied to the a-Si(i):H / nc-Si(p):H samples codeposited on glass: samples were dipped in HF or preannealed in N2/air prior to the $\mathrm{Al}$ pad evaporation, or postannealed in $\mathrm{N} 2$, as well as exposed to combinations of those treatments. Note that the value reported in the main text corresponds to a 2 hours annealing in $\mathrm{N} 2$, conform to our standard characterization method.

On Figure 11, we see that all doping preparation can reach $E_{A}$ values of $30 \mathrm{meV}$ upon post-annealing in $\mathrm{N}_{2}$ atmosphere. This effect cannot be attributed to dopant activation since samples annealed before the Al pads depositions did not exhibit such reduction of $\mathrm{E}_{\mathrm{A}}$. However, the samples prepared with $9.5 \mathrm{sccm}$ of $\mathrm{BF}_{3}$ that were dipped in $\mathrm{HF}$ right before the $\mathrm{Al}$ pads evaporation, the $\mathrm{E}_{\mathrm{A}}$ remains high in all the cases, showing that care should be given to surface oxidation. 

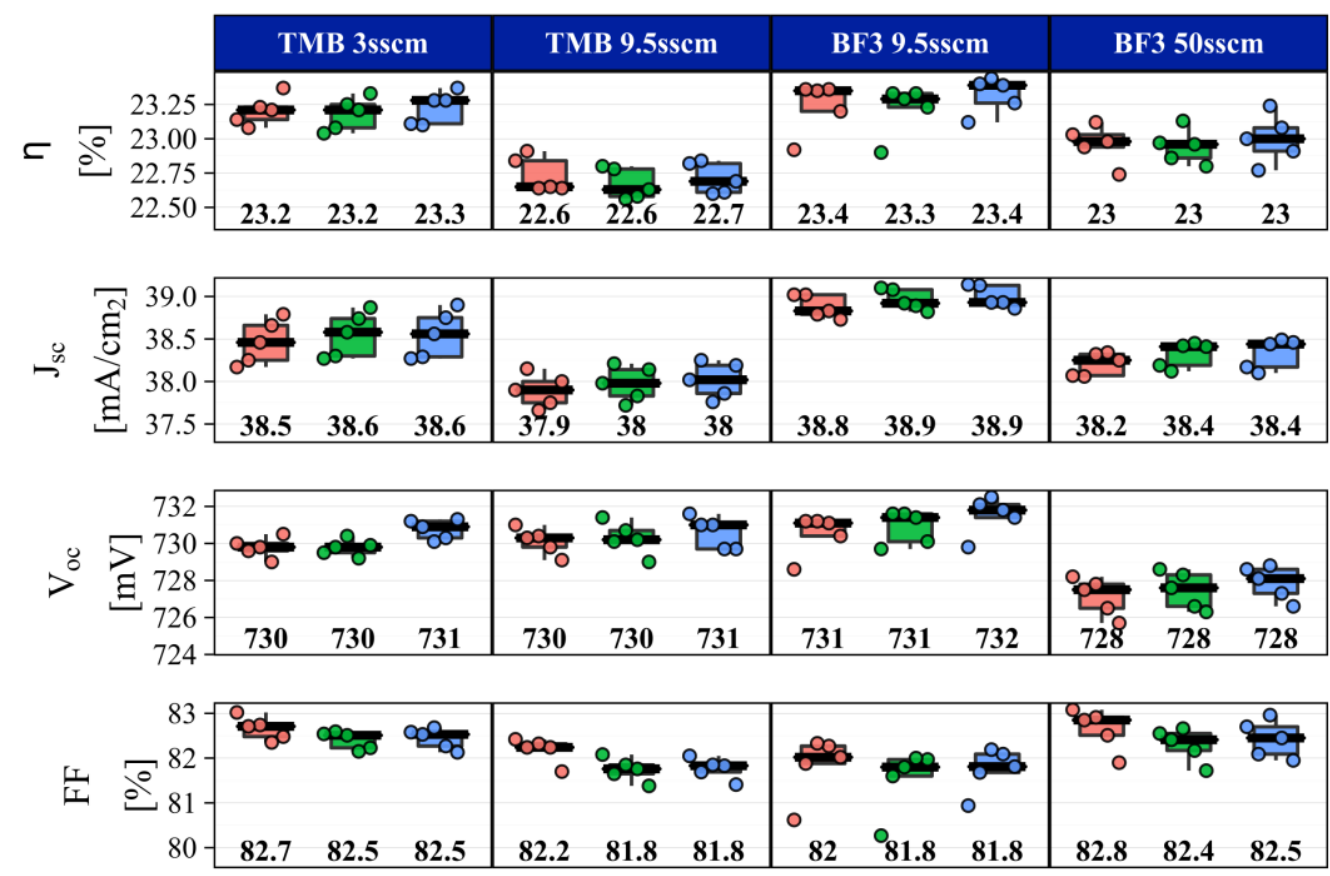

Status
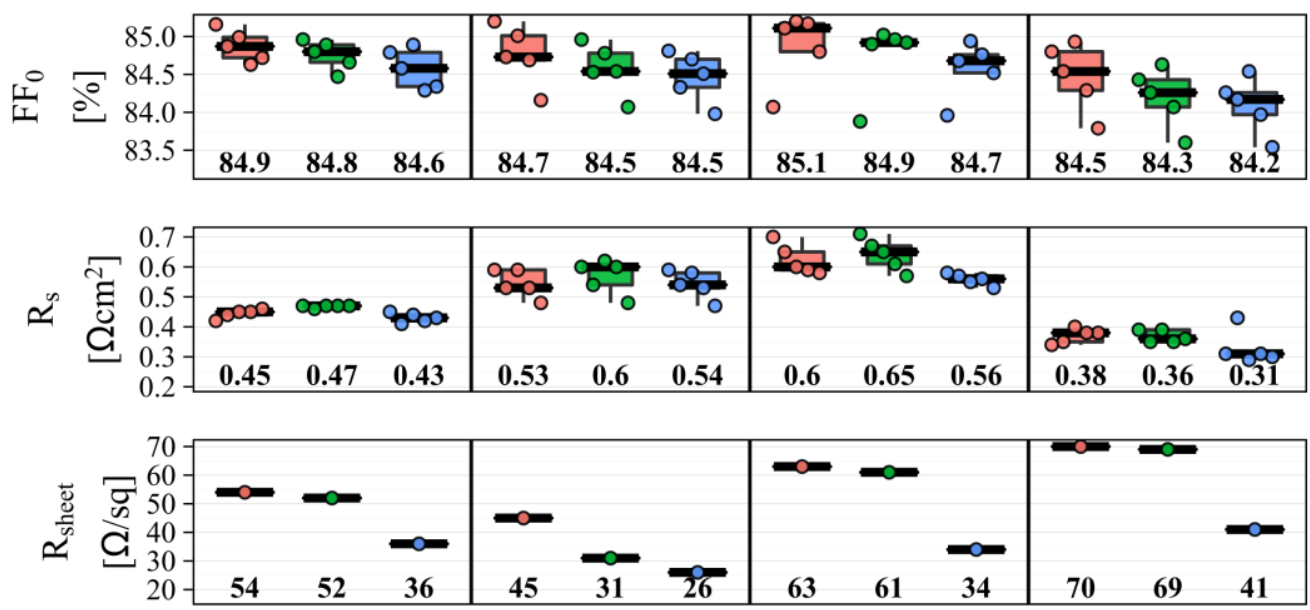

Figure 8. Supplementary data for the IV characterization of the "TMB and BF3 doping series". The different status correspond to values measured just after the Screen-printing step, after 6 days of waiting in the air and after the deposition of the DARC SiOx layers. 
Publisher version:

10.1109/JPHOTOV.2021.3074072

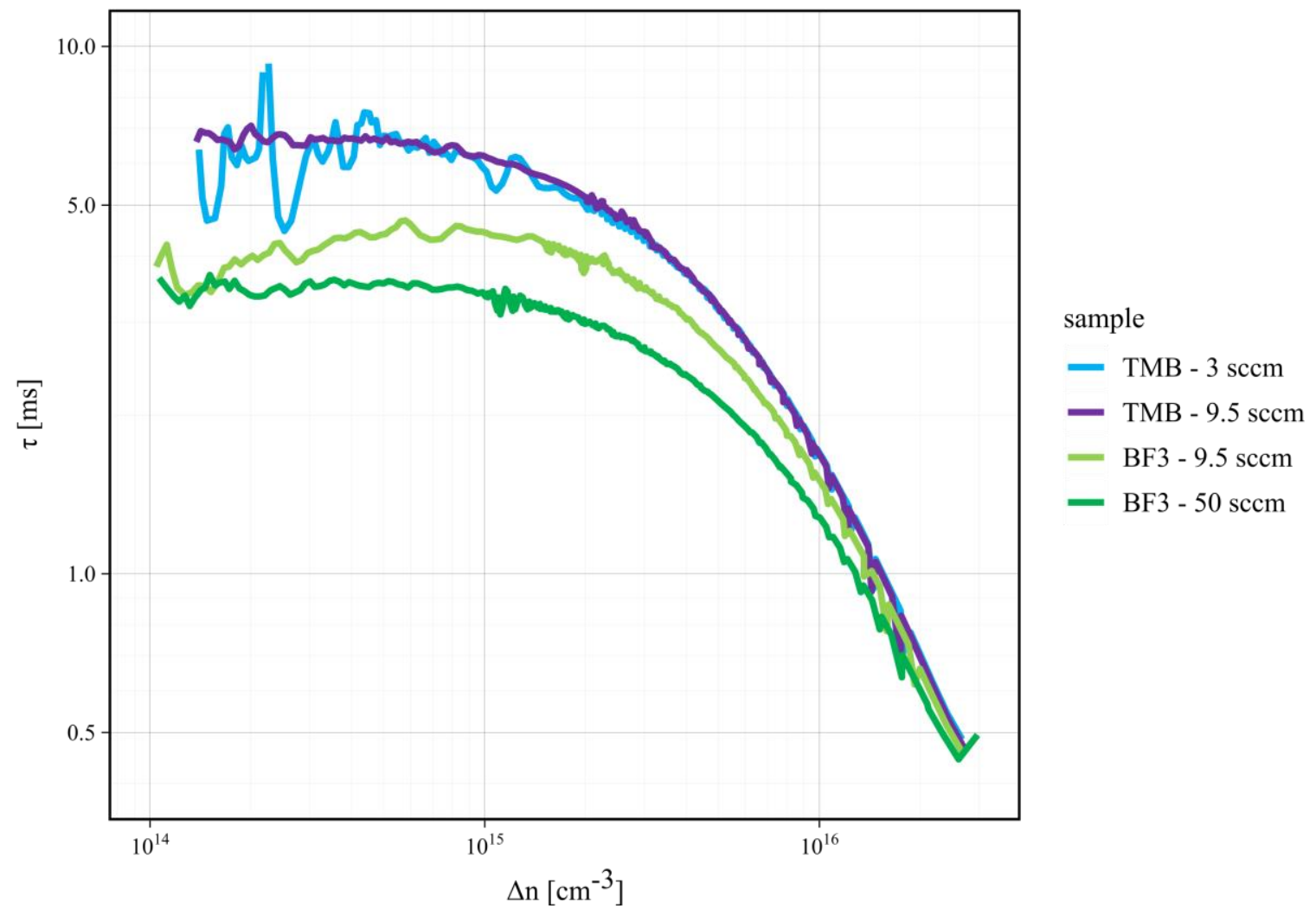

Figure 9. Injection dependent lifetime of solar cell precursors (after PECVD layers deposition) of the "TMB and BF3 doping series". 


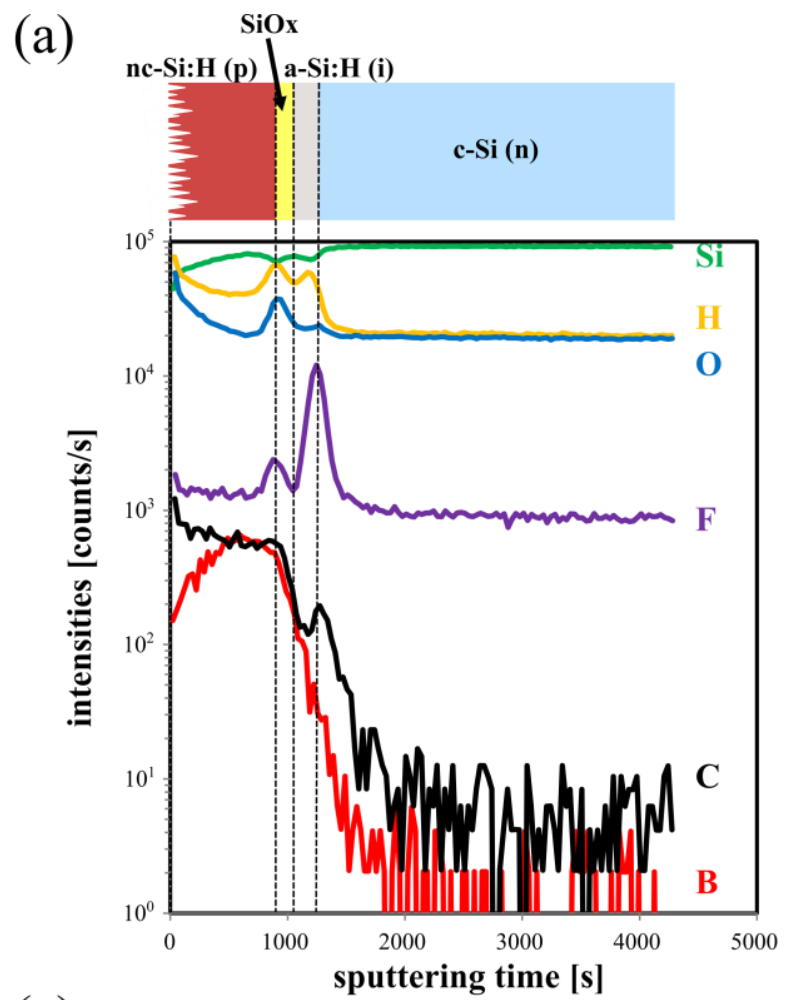

(b)
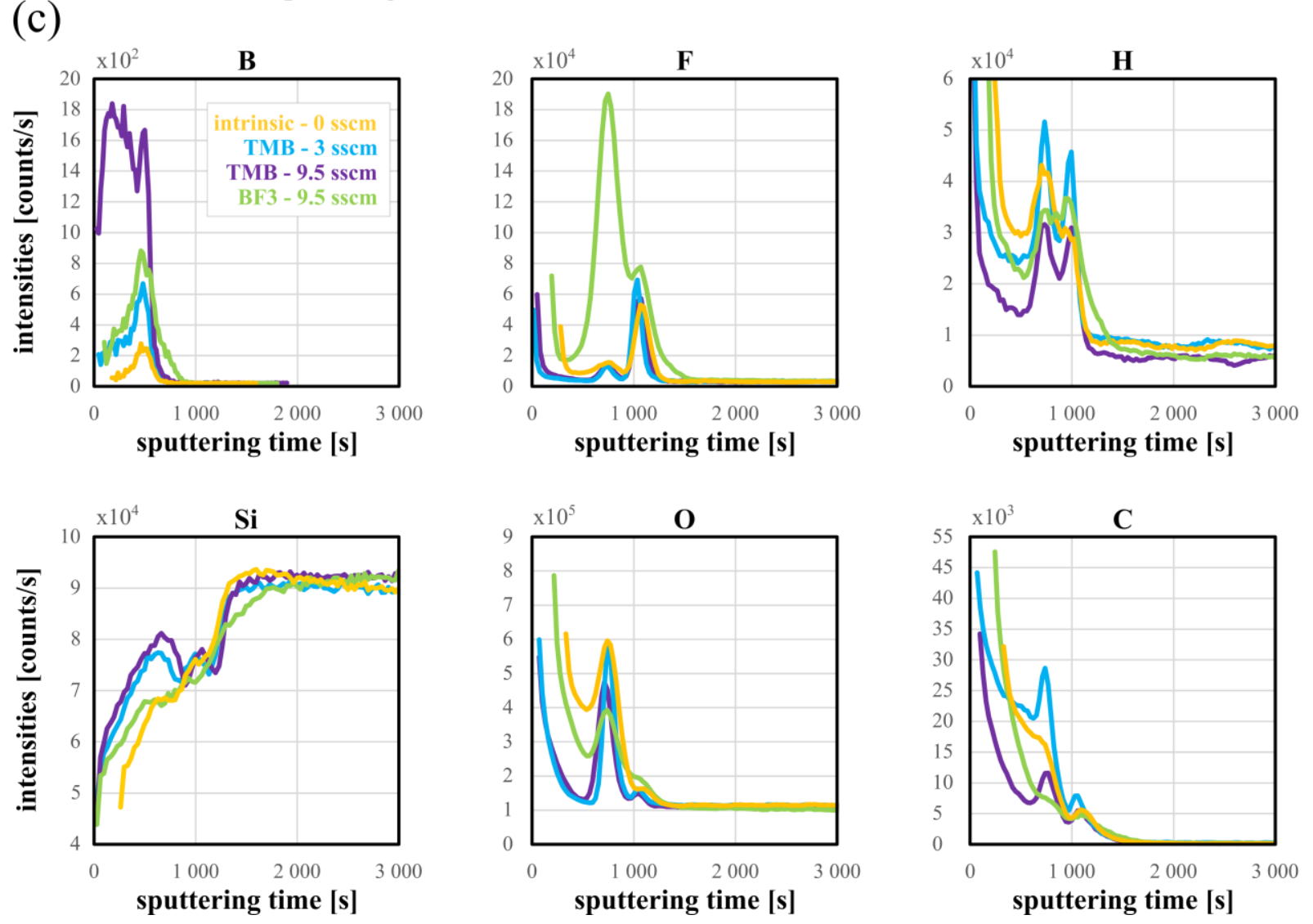

Figure 10. SIMS profile of ip stacks deposited on DSP wafer. (a) Example of a nc-Si:H(p) / SiOx / a-Si:H (i) / c-Si(n) contact analysis, featuring the layer prepared with $9.5 \mathrm{sccm}$ TMB. (b) Activation energy of the nc-Si:H(p) layer for different dopant flow and dopant source and two different batches of samples. (c) Profiles of B, F, H, Si, O, and C compared for different doping flow and dopant source. 
Publisher version:

10.1109/JPHOTOV.2021.3074072

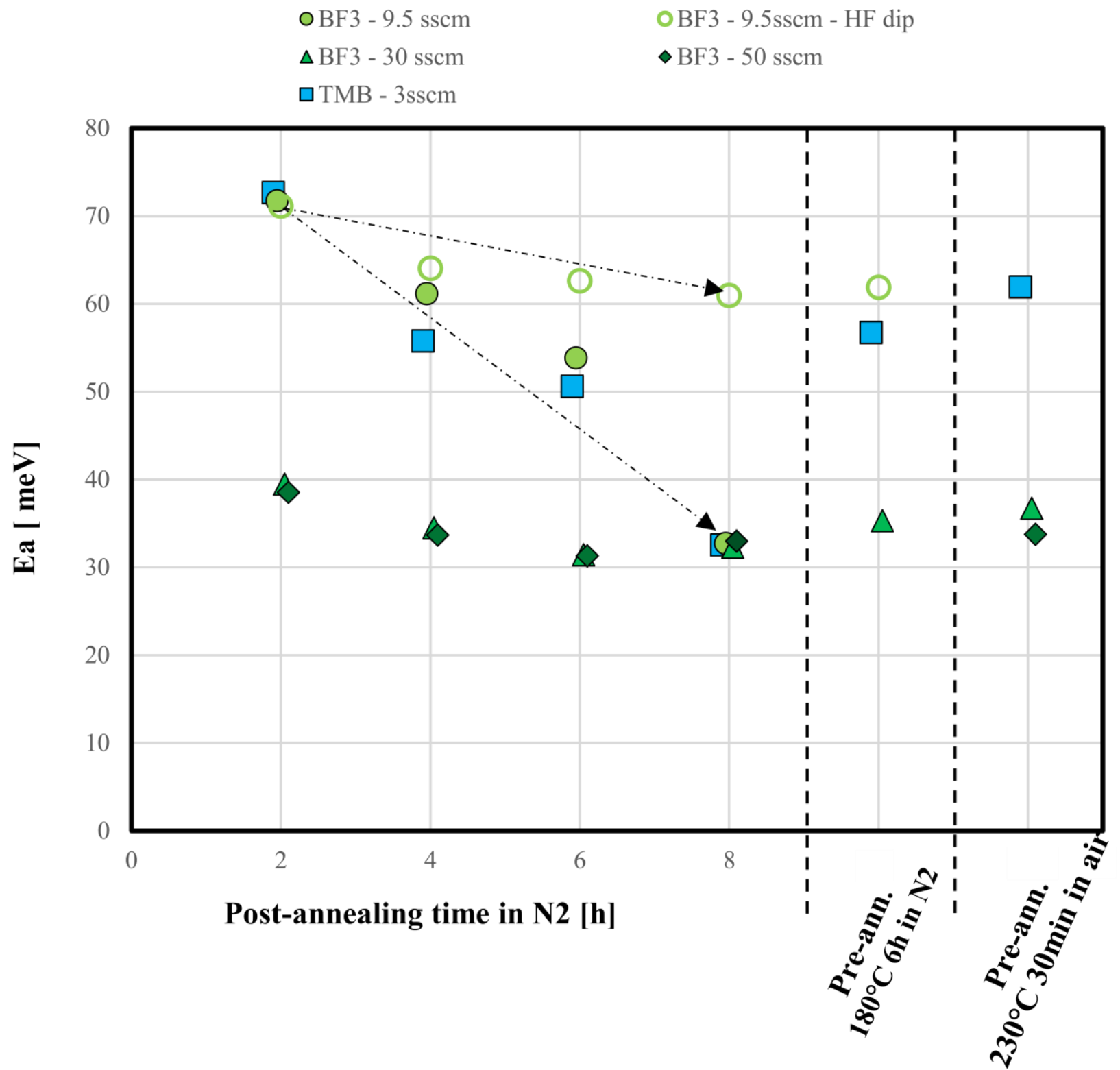

Figure 11. Activation energy of the doping series after different treatments. Pre-annealing and "HF dip" refer to treatment prior to the Al Pads evaporation on contrary to the Post-annealing. Measurements shown in the main text corresponds to the first 2 hours of Post-annealing in $\mathrm{N}_{2}$ 